\title{
BUILDING INFORMATION MODELING ACCEPTANCE AND READINESS ASSESSMENT IN TAIWANESE ARCHITECTURAL FIRMS
}

\author{
Yi-Kai JUAN ${ }^{\mathrm{a}}$, Wan-Ying LAI ${ }^{\mathrm{b}}$, Shen-Guan SHIH ${ }^{\mathrm{a}}$ \\ ${ }^{a}$ Department of Architecture, National Taiwan University of Science and Technology \#43, \\ Sec. 4, Keelung Rd. Taipei, 106, Taiwan, R.O.C. \\ ${ }^{b}$ Department of Industrial Design, Ming Chi University of Technology, \\ No. 84 Gungjuan Rd., Taishan Dist., New Taipei City 24301, Taiwan, R.O.C.
}

Received 20 Mar 2015; accepted 10 Aug 2015

\begin{abstract}
Building information modeling (BIM) has received considerable recognition in the architecture, engineering, and construction (AEC) industry because it can potentially reduce costs and delivery time and improve quality. Conscious of the benefits derived by adopting BIM, the Taiwanese government is planning to enact a policy that would incorporate BIM-based e-submission into the Taiwanese building permit review process, revolutionizing the local AEC industry. Nevertheless, the effects of BIM application are unpredictable. The aim of this study was to investigate the current status of BIM adoption in 224 Taiwanese architectural firms, assess how accepting and ready the firms were to implement BIM, and create a predictive model that can be used by decision makers who are considering adopting BIM. The results revealed that approximately onethird of the firms surveyed had already adopted BIM-based tools. More than half of the firms were willing to use BIM-based tools to streamline the building permit review process; however, their willingness was strongly influenced by governmental policies, competitor motivation, financial incentives, and technological support. The challenges, problems, and opportunities related to adopting BIM were discussed. Lessons learned from the experiences of the Taiwanese firms may be useful to firms facing similar situations and challenges in other countries.
\end{abstract}

Keywords: building information modeling (BIM), building permit review process, architectural firms, organizational readiness, technology acceptance, artificial neural network (ANN).

\section{Introduction}

Research related to building information modeling (BIM) applications have been explored widely in academia and architecture, engineering, and construction (AEC) and facility management (FM) industries (Arayici et al. 2011; Azhar 2011). BIM can be used for several purposes according to various project phases, including visualization, drawings, and cost estimation at the planning stage; forensic analysis and conflict, interference, and collision detection at the design stage; code review and forensic analysis during the permit review process; fabrication or shop drawings and construction sequencing at the construction stage; and facility and maintenance management at the operation stage (Azhar 2011). Numerous studies and projects have directly and indirectly verified that using BIM can facilitate information integration during the building life cycle and is beneficial to building projects (Eastman et al. 2009; Singh et al. 2011). The information integration process enables efficient collaboration and communication among project participants working in cross-organizational environments (Goedert, Meadati 2008; Rezgui et al. 2013).
In Taiwan, people who plan to build, renovate, or retrofit a building must apply for a building permit review. The current review process mainly involves scanning and converting documents into PDFs, which is time-consuming and complex. In addition, this traditional review process creates a heavy administrative burden and is inefficient in terms of project implementation. After the Singaporean government effectively implemented the e-Plan Check (an automated electronic drawing review system) (Eastman et al. 2009), the Taiwanese government, recognizing the benefits of BIM adoption, has been planning to enact a policy that would incorporate BIM-based e-submission into the building permit review process and revolutionize the local architectural firms. Particularly, architectural firms would be the first to be affected by BIM adoption because they are involved in the early stages of building projects.

Adopting BIM in Taiwan is a public-oriented project. The government is attempting to provide a platform and infrastructure for enterprises to improve their industrial com- 
petitiveness. However, before enacting this new policy, the effects of BIM application are unpredictable (Lee, Yu 2013; Lee et al. 2015), and various doubts and considerations must be addressed. For example, the percentage of architectural firms in Taiwan that have already adopted BIM-based tools and the general attitude firms have toward adopting BIM to execute projects and using BIM-based e-submission for building permit reviews must be determined. In addition, whether firms are ready and able to adopt BIM, and the major challenges, problems, and opportunities associated with BIM adoption need to be ascertained. Because this policy will transform the industry structure, the impact of policy implementation warrants further investigation.

Although several studies have investigated BIM software development, technological applications, and system improvement (Howard, Björk 2008; Samuelson, Björk 2013), research conducted to determine the relationship between BIM application and changes in the industrial environment is relatively scarce (Tsai et al. 2014). During the last decade, development of AEC and FM industries has been greatly influenced by the evolution of information technologies (IT), such as advances in information systems for enterprise resource planning (ERP), supply chain management, and knowledge management (KM) (Lin 2014; Rezgui et al. 2010). BIM is rapidly becoming the next trend in IT innovation, and may affect AEC and FM participants from the public and private sectors (Azhar 2011). To provide insight into the Taiwanese government and architectural firms and facilitate feasible BIM adoption, this research had three objectives:

- Investigate the current status of BIM adoption in 300 Taiwanese architectural firms;

- Develop a system that can be used to assess the readiness and acceptance of a firm to adopt BIM and BIM-based building permit review process;

- Establish a predictive model based on artificial neural networks (ANNs) that can be applied by architectural firms to evaluate the feasibility of adopting BIM in the future.

\section{Background study and literature review}

\subsection{Building information modeling and collaboration in the AEC industry}

BIM can potentially facilitate information integration at different stages of a building project, thereby improving collaboration among architects, engineers, and contractors (Taylor 2007). This cross-organizational collaboration provides an opportunity for participants to share risks, incorporate new technologies and markets, improve colocation, and pool complementary skills (Harty 2005). However, cross-organizational collaboration also creates diverse challenges. For example, introducing new technologies into an organization to stimulate organizational change is frequently met by resistance from its members (Bechky 2003). After the technologies have been adopted, members must learn to use the technologies for crossorganizational collaboration and communication (Taylor
2007). In a building project, architects generally play a key role in initiating BIM adoption because they are prominent in establishing information models for project integration. Investigating the current status, acceptance, and readiness to adopt BIM in architectural firms is critical to effective BIM implementation (Arayici et al. 2011).

\subsection{Building information modeling system potential in the building permit review process}

The building planning and design is the critical initial stage during which most information models are produced; the building permit review is among the most crucial aspects of this stage. Various studies have attempted to establish a basic framework, such as applying digital technology tools and information systems (Boukamp, Akinci 2007; Goedert, Meadati 2008), that can be used to facilitate the building permit review process. For example, the Singaporean government has lead the promotion of computer-assisted building permit reviews, first in 2001 by implementing an electronic drawing review system called e-Plan Check, and again in 2006 by incorporating three-dimensional (3D) automated electronic building reviews into standard procedures. In addition, it initiated a pilot test of a 3D BIM automated electronic review system to promote BIM application (Eastman et al. 2009; Kim, Yu 2014).

Unlike in Singapore, where the government is the dominant force promoting BIM application, BIM is largely industry-driven in the United States. In contrast with Singapore's top-down approach, individual industry players in the US have initiated BIM adoption, prompting the government to gradually implement corresponding policies. Because of governmental incentives and strong promotion by software suppliers, many architectural firms are willing to invest in BIM software and training. BIM-based permit reviews will likely become a trend in US architectural firms, and the private sector will probably adopt them as well, resulting in substantial advances in BIM adoption (Wong et al. 2011).

Regardless of whether the adoption model used is the top-down approach of the Singaporean government or the bottom-up approach promoted in the US, the notion of BIM promotion is the same: building information models and building codes reviews are the two core elements of computer-assisted reviews used in the building permit system. As BIM technology develops, implementing BIM in the building permit review process is believed to become more feasible and inevitable, despite the severe challenges encountered when integrating BIM with applicable building codes into various project types (Kim, Yu 2014).

\section{Models used to assess building information mod- eling acceptance and readiness}

\subsection{Technology acceptance model}

Innovation in IT can enhance the competitiveness of organizations (Ashurst et al. 2012). Many recent studies 
have explored the relationship between IT acceptance and organizational management. Lin and Shao (2000) believed that user participation in developing an IT system was essential to its effective implementation in an organization. Kaplan and Norton (1992) also asserted that active participation by future users in the design of an information system would improve organizational success in terms of higher system usage, greater user acceptance, and increased user satisfaction. Nevertheless, Jarvenpaa and Staples (2000) cautioned that personal attitudes toward adopting new technology may create risks, such as decreased learning motivation, employee resistance, and problems during the adjustment period.

Among the most widely known technology acceptance theories is the technology acceptance model (TAM), which affords a basis on which to explore external factors affecting user internal beliefs, attitudes, and intentions when using an information system (Davis 1989). The TAM is an information system theory that can be applied to explain how users accept and use technology, and includes two key variables: perceived usefulness (PU) and perceived ease of use (PEU). PU pertains to the degree to which people believe that using a system will enhance job performance, and PEU is defined as the degree to which people believe that using a system will be effortless (Godoe, Johansen 2012; Davis 1989). The TAM is therefore suitable for exploring the PU and PEU related to BIM acceptance in construction organizations (Lee, Yu 2013; Lee et al. 2015).

In addition to the TAM, many studies have indicated that introducing IT has created opportunities for organizations to facilitate knowledge processes, thus enhanc- ing knowledge sharing and creation within and among organizations (Assegaff et al. 2011). The result of implementing knowledge management systems (KMSs) is further related to organizational objectives focusing on improved performance, competitive advantage, and innovation (Zhang et al. 2009). A KMS, which includes the four key variables of people, technology, processes, and content (King et al. 2002), is a continual process used to assess the technology acceptance, beginning from the IT introduction and extending to the knowledge process and performance improvement.

A balanced scorecard (BSC), which is another element that has been applied to measure performance, includes four variables: financial aspects, customers, internal business processes, and learning and growth (Ashurst et al. 2012). Organizational performance is affected by technology acceptance and readiness, and information system quality (Kuo 2013). The TAM, KMS, and BSC are highly related. A BSC can be introduced to ensure business activities are in line with the organization vision and strategy, improve internal and external communication, and monitor organizational performance.

Therefore, when assessing technology acceptance (i.e., BIM adoption), dimensions including the TAM, KMS, and BSC should be comprehensively considered to develop an acceptance assessment model. To explore the views architects have regarding including BIM in the building permit review process, and their experiences of and willingness to use BIM, the TAM, KMS, and BSC attributes were used as a basis with which to categorize four perspectives of BIM acceptance assessment: BIM technology usage, external environments, internal factors,

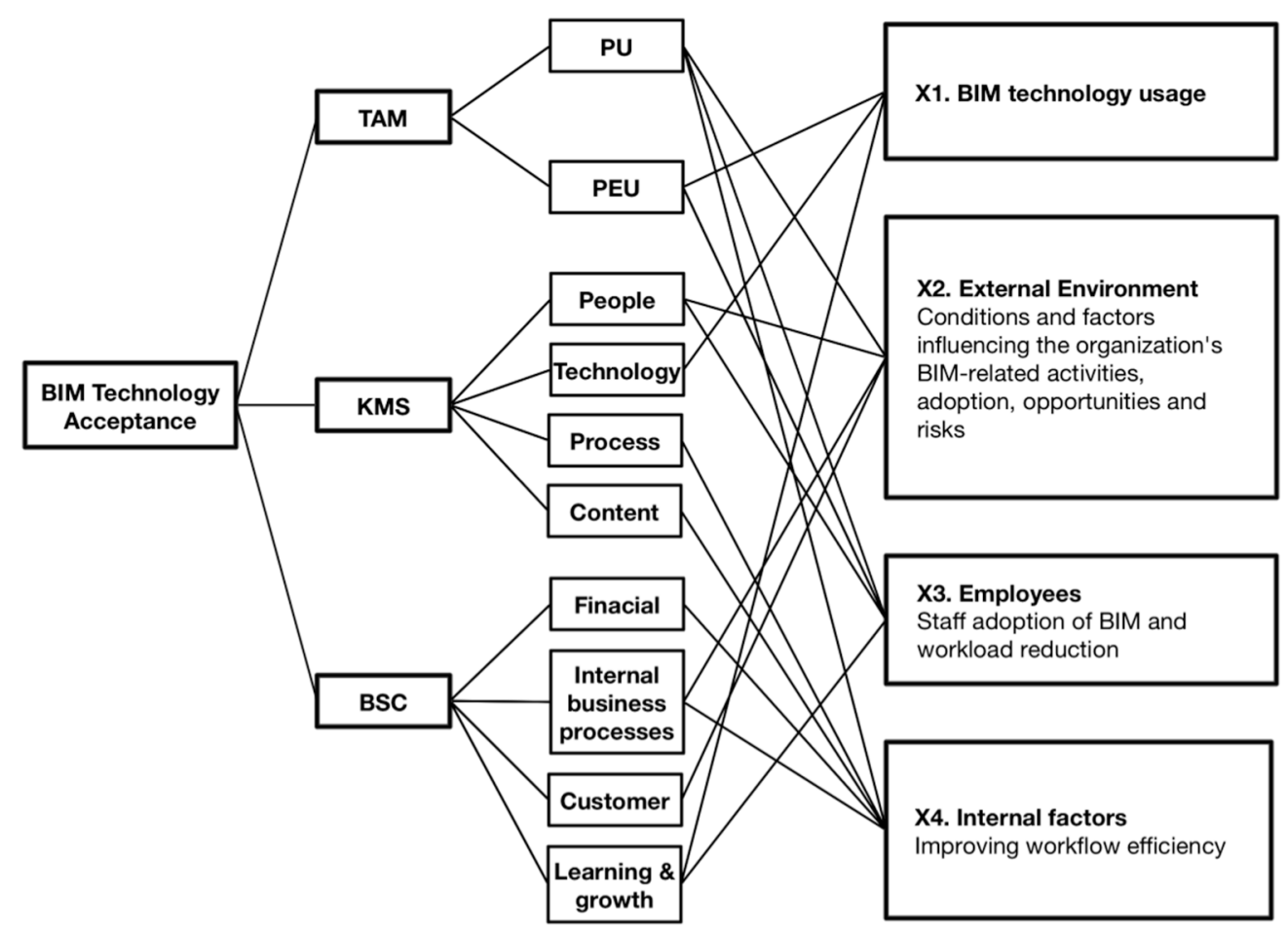

Fig. 1. The framework of BIM acceptance assessment 
and employees (also see Appendix A). Figure 1 depicts the framework and Table 1 shows the BIM acceptance assessment:

- BIM technology usage: determine the willingness to use BIM and the actual BIM use in business operations.

- External environments: understand whether BIM facilitated the building permit review process and improved project communication, client satisfaction, engineering disputes, competitor influence, and business development.

- Internal factors: ascertain whether BIM improved work efficiency, reduced project costs, increased training costs, and promoted organizational innovation.

- Employees: determine the ease of BIM use and whether it reduces employee workloads.

\subsection{Organizational readiness model}

Introducing a new technology into an organization inevitably causes organizational change, called technologybased change, meaning the workflow, production methods,

Table 1. BIM acceptance assessment

\begin{tabular}{l|l}
\hline \multicolumn{1}{c|}{ Attributes } & \multicolumn{1}{c}{ Assessment items } \\
\hline X1. BIM & X1-1 The architect's actual usage of \\
technology usage & BIM software \\
& X1-2 Willingness to join the \\
experience program
\end{tabular}

controls, and information systems of an organization are reformed by adopting a new technology (Patterson et al. 2003). However, effectively implementing new technology is critically related to organizational readiness for change (Khazanchi 2005). Some studies have confirmed that failing to establish sufficient readiness accounts for half of all unsuccessful organizational change efforts (Weiner 2009).

Unlike the BIM acceptance assessment, which integrates the TAM, KMS, and BSC attributes and pertains to assessing attitudes toward and subjective perceptions of BIM adoption, the readiness model, which is based on the theory of readiness for workplace change management (RWCM) proposed by Becker (2004), was developed to assess whether an organization is ready to adopt BIM. According to RWCM studies conducted by Becker (2004), six key organizational factors (leadership, business performance, operating environment, organizational culture, technological environment, and workforce demographics) are defined to assess organizational readiness to adopt new workplace strategies. Because RWCM is based on an organization's readiness for change, the RWCM can facilitate understanding interest in and commitment to changing longstanding attitudes and behaviors related to how new technology can be adopted and deployed. Therefore, in this study, based on the notion of RWCM, a panel of experts including 12 professionals (architects, BIM software engineers, BIM consultants, researchers, and scholars) from academia and industry was invited to discuss and revise the readiness assessment tool. This tool was designed to help architectural firms assess organizational readiness to adopt BIM and reflect upon their organizational work practices and current technology capabilities. Table 2 shows the revised readiness assessment (also see Appendix B).

\subsection{Relationship between technology acceptance and organizational readiness}

The technology acceptance assessment was focused on exploring external factors affecting user internal beliefs, attitudes, and intentions to accept and use new technology. The organizational readiness assessment was developed to ascertain whether an organization is internally ready to adopt a new technology. Venkatesh (2000) contended that organizational readiness is highly related to the technology acceptance of people within an organization. Tsikriktsis (2004) proposed that people are willing to accept a new technology when they are ready for organizational change. Lin et al. (2007) integrated technology readiness into the TAM to evaluate e-service systems used by consumers, indicating that technology readiness affects consumer technology acceptance. Kuo (2013) verified that user readiness in a technology-supported environment can be regarded as an antecedent factor of effective technological innovation adoption. Mahamadu et al. (2014) developed a conceptual model to examine the interrelationship between determinants of acceptance and 
Table 2. BIM organizational readiness assessment

\begin{tabular}{|c|c|}
\hline Attributes & Assessment items \\
\hline X5. Leadership & $\begin{array}{l}\text { X5-1 CEO's leadership and executive } \\
\text { power } \\
\text { X5-2 CEO's leadership style on } \\
\text { workplace } \\
\text { X5-3 CEO views the need for change } \\
\text { to use BIM }\end{array}$ \\
\hline $\begin{array}{l}\text { X6. Business } \\
\text { performance }\end{array}$ & $\begin{array}{l}\text { X6-1 The integrity of the } \\
\text { organizational structure } \\
\text { X6-2 The complexity of construction } \\
\text { business type } \\
\text { X6-3 Financial soundness }\end{array}$ \\
\hline $\begin{array}{l}\text { X7. Operating } \\
\text { environment }\end{array}$ & $\begin{array}{l}\text { X7-1 Hardware support } \\
\text { X7-2 Willingness to invest in new } \\
\text { equipment } \\
\text { X7-3 Development of operation } \\
\text { database }\end{array}$ \\
\hline $\begin{array}{l}\text { X8. Organizational } \\
\text { culture }\end{array}$ & $\begin{array}{l}\text { X8-1 Culture of organization values } \\
\text { risk-taking } \\
\text { X8-2 Sharing of information and ideas } \\
\text { X8-3 Business and design innovation }\end{array}$ \\
\hline $\begin{array}{l}\text { X9. Technical } \\
\text { environment }\end{array}$ & $\begin{array}{l}\text { X9-1 Technology support from } \\
\text { colleagues } \\
\text { X9-2 Continuous education and } \\
\text { training for employees } \\
\text { X9-3 Supply chain management }\end{array}$ \\
\hline X10. Workforce & $\begin{array}{l}\text { X10-1 Employees' computer ability or } \\
\text { technology acceptance } \\
\text { X10-2 Employees already have BIM } \\
\text { technology ability } \\
\text { X10-3 Firm's staff turnover percentage }\end{array}$ \\
\hline
\end{tabular}

readiness of the supply chain and its impact on achieving the maturity of BIM adoption. Based on the aforementioned studies, we inferred that the relationship between technology acceptance and readiness is substantial, and readiness is the key to successful acceptance of technology adoption. Both technology acceptance and readiness should be accounted for to create a comprehensive assessment system of BIM adoption.

\section{Method}

This study had three objectives: (1) investigate the current status of BIM adoption in 300 Taiwanese architectural firms; (2) develop a system that can be used to assess the readiness and acceptance of a firm to adopt BIM and BIM-based building permit review process; and (3) establish a predictive model based on ANNs that can be applied by architectural firms to evaluate the feasibility of adopting BIM in the future. Various methods were employed to achieve each objective.

First, a large-scale survey was conducted to investigate BIM adoption in 300 Taiwanese architectural firms. Second, the organizational readiness assessment model was developed to ascertain whether these firms were ready to adopt BIM. Acceptance and readiness assessment was quantitatively transformed into scales. Reliability and factor analysis were then used to refine the acceptance and readiness factors (variables) that may affect the decision of BIM adoption. Third, based on the indentified variables from the reliability and factor analysis, a predictive model based on the ANN method to evaluate the feasibility of BIM adoption was developed.

\section{Results and discussion}

\subsection{Current status in the industry}

The analyzed data were acquired from a survey of 300 architects administered at the annual Taiwan Architects Association member meeting in 2010. Respondents completed a questionnaire assessing the technology acceptance and organizational readiness of their firms. A total of 300 questionnaires were distributed and the valid response rate was $75 \%$ (224 of 300 were returned). The professional architects included in this study were experienced and active in the Taiwanese architecture market. At the time of the investigation, 191 of the architects were principal architects at firms and 33 were senior architectural designers or mangers who were in charge of or involved in the firms' operation for more than 10 years. Office, housing, and public building projects had comprised their main source of professional work over the past 10 years. Figure 1 and Tables 1 and 2 show the assessment item framework. The data indicated that respondents had been employed by their firms for an average of 13.2 years (ranging from less than 1 year to 48 years) and the average firm capital was approximately US\$100,000 (ranging from US\$30,000 to US\$6,600,000). Among the firms, $32 \%$ had already adopted BIM-related tools.

Of the respondents, $60 \%$ admitted that they were reluctant to adopt BIM software mainly because the switching cost was too high and technological support for BIM was limited. The result was similar to the previous study revealing that initial investment cost of BIM tools was too expensive from owner's perspectives (Tsai et al. 2014). In addition, 60\% indicated that if they were provided with trial BIM software programs, they would feel more inclined to adopt BIM in the future. In other words, to accelerate BIM-based e-submission, the government, organizations, and institutions should continually offer education and training programs, software trials, and policy promotions. Among the respondents, 21\% were dissatisfied with the current building permit review process and only $38 \%$ believed that BIM application would facilitate the process. Moreover, 53\% were willing to change and adopt BIM for building permit reviews if a government policy required them to submit electronically. However, their major concern was whether BIM-based e-submission could actually simplify the review process.

The results indicated that $93 \%$ of the respondents would be inclined to adopt BIM if their competitors had already done so, suggesting that promoting BIM application in Taiwan corresponds with the theory of competitive convergence, that companies follow pioneers' 
strategies to maintain competitiveness in the industry. Of the respondents, $54 \%$ and $49 \%$ believed that using BIM could improve communication efficiency and information exchange quality, respectively. Moreover, $51 \%$ and $47 \%$ stated that applying BIM could facilitate architectural design innovation and expanding new businesses, respectively.

As for the organizational readiness assessment, the results from the survey also indicated that $81 \%$ of the surveyed firms claimed that no effective technology or software support that could enable them to adopt BIM existed; $83 \%$ believed that their employees possessed few capabilities and skills to use BIM technology; and $90 \%$ encouraged employees to enrol in training and education programs. These results revealed that most firms were unready to implement BIM and that Taiwan has a large market for BIM training and education. The results were also consistent with previous research results indicating that enhancing user competence of BIM use through education and training is critical ( $\mathrm{Xu}$ et al. 2014). Of the firms surveyed, $75 \%$ indicated that they had low risk thresholds for organizational change and insufficient IT equipment, resulting in strong resistance to BIM promotion in Taiwan; quickly changing organizational culture is difficult. More than $50 \%$ of the firms were unwilling to invest in IT equipment and BIM software. This wait-and-see attitude may be influenced by governmental policies, industrial development, and the provision of training or educational programs, an inference that is supported by research implying that BIM adoption is mainly influenced by associations or the government, and that user attitudes are critical to operation processes in the context of BIM environments (Xu et al. 2014).
In summary, most Taiwanese architectural firms are unready to implement BIM because of the organizational cultures; insufficient technology support, education, and training; and lack of BIM software. However, according to the readiness assessment (Fig. 2), firms that had adopted BIM demonstrated a higher level of readiness than those that had not. This observation can benefit the government when rethinking BIM adoption and promotion strategies, and reflects that one of the keys to success is increasing firm readiness.

\subsection{Predictive model for architectural firms}

\section{Reliability and factor analysis for technology acceptance assessment factors}

Cronbach's $\alpha$ coefficient was used to analyze the reliability of each measured attribute. Based on the collected data, the overall Cronbach's $\alpha$ coefficient of technology acceptance assessment was 0.953 and the individual $\alpha$ coefficients for X1-X4 were 0.811, 0.918, 0.848, and 0.93 , respectively. In addition, removing some items, such as X2-1 and X3-2, slightly improved the value of Cronbach's $\alpha$. The factor analysis method was then applied to refine the major factors affecting architect acceptance of BIM. Examination of the Kaiser-Meyer-Olkin (KMO) measure of sampling adequacy suggested that the sample used in this research was factorable $(\mathrm{KMO}=0.917)$; the correlation patterns were relatively compact, and thus, the factor analysis would yield distinct and reliable factors.

The data indicated that the final explained variance was $70.28 \%$. Two components (factors) with eigenvalues greater than 1 were extracted, and factors with loadings of less than 0.6 were excluded. Thus, the analysis yielded a solution that satisfied two factors with

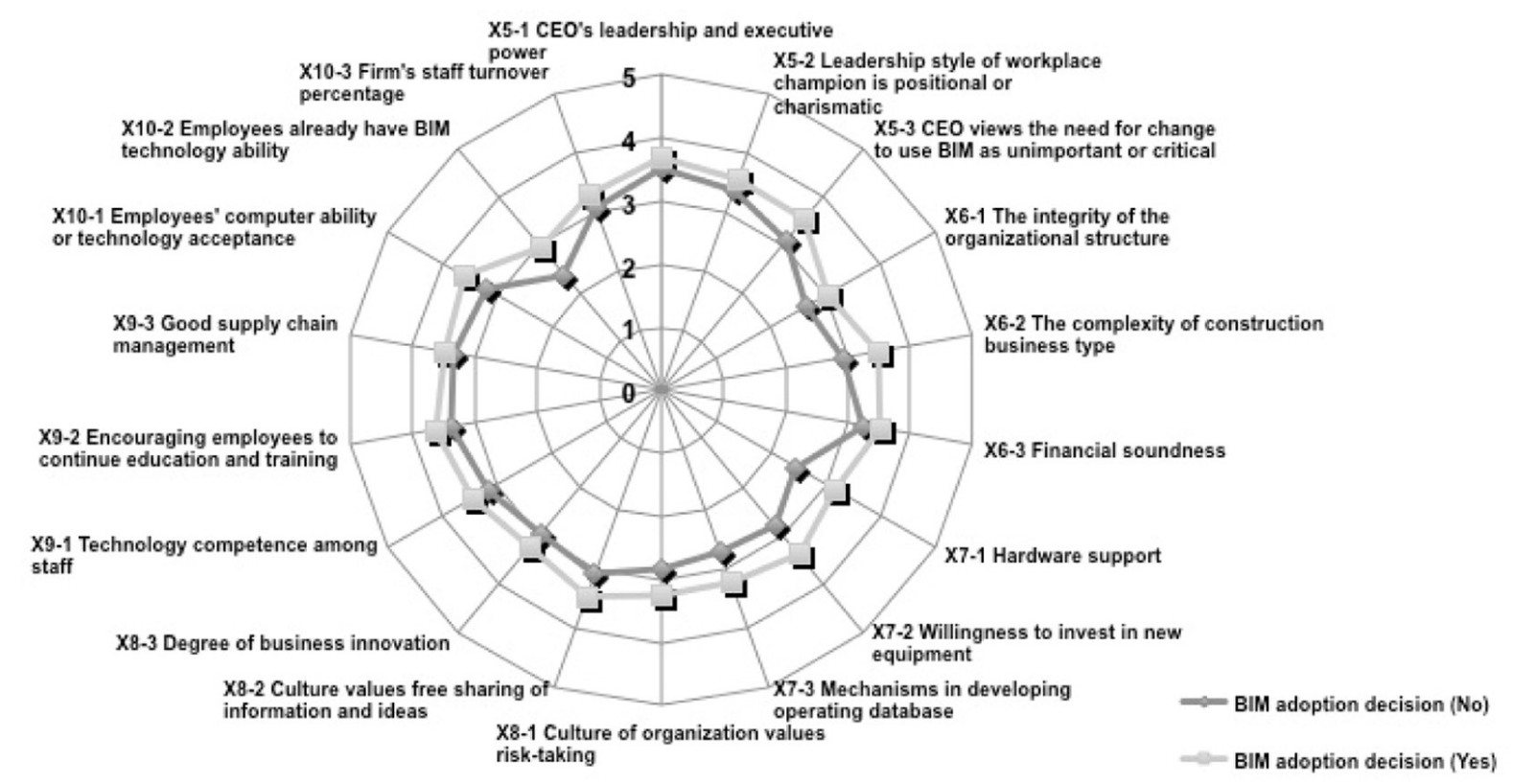

Fig. 2. Organizational readiness assessment for BIM users and non-users 
eight items $(\alpha=0.932)$ and an additional three items $(\alpha=0.866)$, implying that the reliability of the component classification was significant.

The eight items that were loaded onto Component 1 were X2-7, X2-6, X2-5, X2-4, X2-8, X4-6, X2-9, and $X 4-1$. The items appeared to be related to problems arising from project implementation and collaboration among various participants. Therefore, Component (factor) 1 was called "Project collaboration and communication (X'1)". The three items that were loaded onto Component 2 were X4-7, X4-8, X3-1. The items were mostly related to technological concerns, including technological environment improvements, investments, operations, and acceptance. Accordingly, Component 2 was labelled "Technology investment and training (X'2)".

\section{Reliability and factor analysis for organizational readiness assessment factors}

Similarly, the overall Cronbach's $\alpha$ coefficient of the organizational readiness assessment was 0.918 , and the individual $\alpha$ coefficients for X5-X10 were $0.812,0.835$, $0.858,0.884,0.868$, and 0.922 , respectively. Removing some items, such as X5-3 and X10-2, increased the Cronbach's $\alpha$ value. The final explained variance was $74.15 \%$. Three components (factors) with eigenvalues greater than 1 were extracted, and factors with loadings of less than 0.6 were excluded. In this case, five items were loaded onto Component 1: X7-1, X7-2, X7-3, X6-1, and X81 , and the component was called "Organizational structure and operating environment (X'3)". Four items were loaded onto Component 2: X9-1, X9-2, X9-3, and X10-1, and the component was called "Technical environment and support (X'4)". Two items were loaded onto Component 3: X5-1 and X5-2, and the component was called "Leadership and executive power (X'5)".

\section{ANN model architecture}

After using reliability and factor analysis, five new variables ( $\left.X^{\prime} 1-X^{\prime} 5\right)$ were identified. To enable architects to evaluate the feasibility of using BIM in their firms, a predictive model based on the ANN method was developed. Among the numerous ANN types, a back-propagation (BP) learning algorithm with feed-forward architecture was used to construct the ANN model. BP is basically a multilayer feed-forward network that typically comprising one input layer, one or more hidden layers, and one output layer. The BP network searches for the minimum of the error function in weight space using the gradient descent method. It can be used to learn and store numerous mapping relations of an input-output model to determine a function that most accurately maps a set of inputs to the correct output. Because of its convenience, efficiency, and potential to improve the performance of neural networks and enhance the model prediction accuracy (Kumar et al. 2013; Ling, Liu 2004), BP was selected as the major method through which to operate the ANN in this study. Figure 3 depicts a simplified ANN model. The input layer presents data to the network. The size of the input layer, or number of nodes, is determined by the number of key factors (variables). In this study, five assessment variables ( $\left.X^{\prime} 1-X^{\prime} 5\right)$ were identified as inputs to assess organizational acceptance and technology readiness. Hidden layers act as layers of abstraction, pulling features from inputs. The number of nodes in the hidden layers was decided by trial and error (Ling, Liu 2004). The output layer has one node, which is the variable of BIM adoption decision (Y: BIM adoption decision, yes or no). The numbers of neurons in the input, hidden, and output layers were 5, 10, and 1, respectively. The ANN model was designed and trained using Neuralyst software.

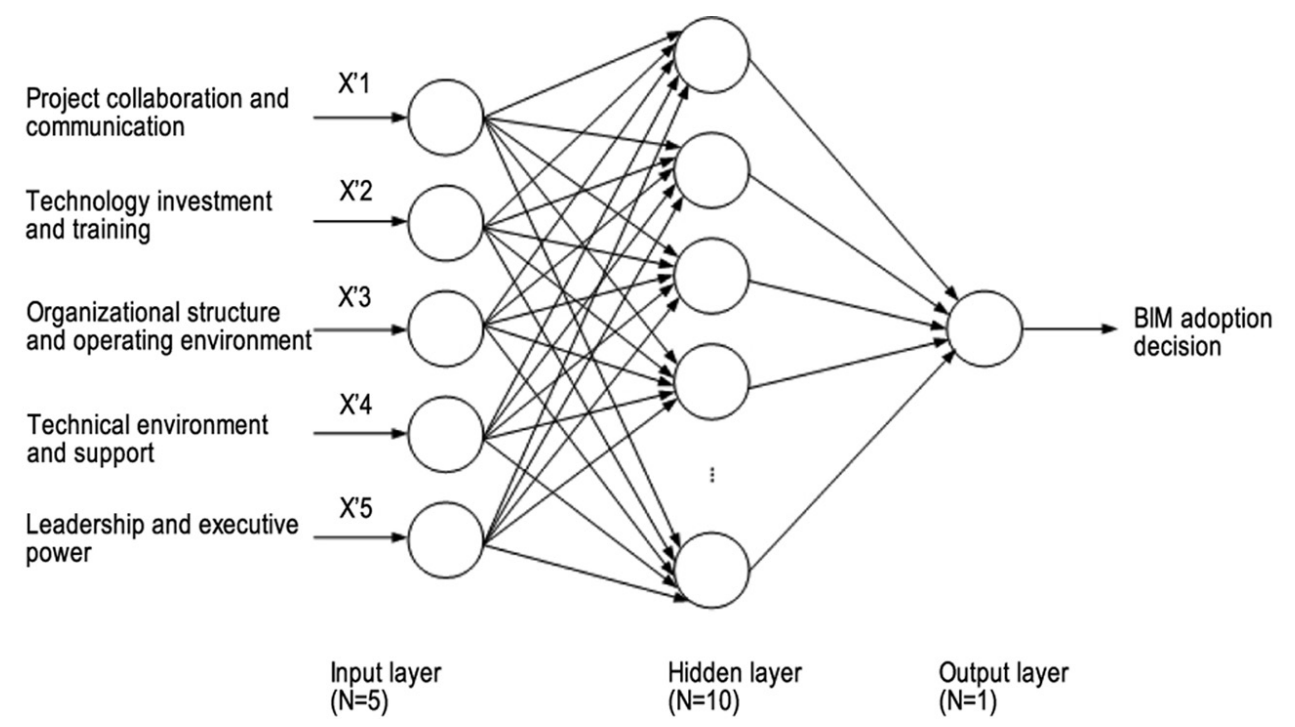

Fig. 3. Network architecture of ANN 
To prevent the ANN from overtraining, training began using only six neurons in the hidden layer and the ANN optimized using 10 neurons in the hidden layer. Among the 224 cases, 160 and 64 cases were randomly designated as training and test cases, respectively, to validate the predictive performance of the ANN model. Figure 4 shows the training curve of the ANN model after 8,000 epochs. Various parameter settings, such as the learning rate $(0.6)$, momentum $(0.8)$, training tolerance $(0.2)$, and testing tolerance $(0.4)$, were further defined. In this setting, the root mean square (RMS) error of the training cases achieved 0.06 . The acceptance and readiness scores of the 64 test cases were then used as inputs, and their BIM adoption decisions (yes or no) were used as outputs to validate the proposed predictive model. The results suggested that the model's overall prediction capability was $81.3 \%$ (RMS error of 0.24 ; only 12 cases were predicted incorrectly among 64 cases), which is adequate to explain the relationship among acceptance, readiness, and the feasibility of BIM adoption. For the future application, the model can estimate the potential for BIM adoption after decision-makers input the value of five variables related to their self-assessment of acceptance and readiness based on Figure 3. The results verified the reliability ( $81.3 \%$ prediction accuracy) of this model and demonstrated that is can be used as an effective decision support tool.

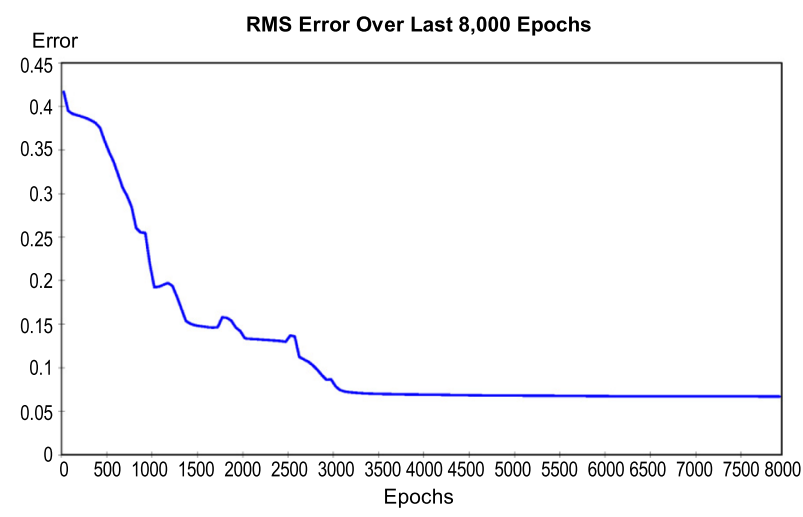

Fig. 4. Training curve of the ANN model

\subsection{Discussions of building information modeling in the building permit review}

Although $32 \%$ of the firms had already adopted BIM tools, most had not considered applying BIM to the building permit review process. The first reason for this may be that most harbored doubts regarding the benefits of BIM adoption to simplify the permit review process. This assumption was verified by the acceptance assessment, which demonstrated that only $38 \%$ of the respondents believed that BIM would facilitate the building permit review process. Second, because architectural firms in Taiwan have not experienced BIM-based e-submission, they cannot conceive how BIM adoption will affect the process.
The interviewees expressed insightful opinions and suggestions regarding BIM-based e-submission in building permit reviews. Although BIM is associated with potential risks, the government and industry should not be overly concerned with these risks, which are outweighed by advantages. A step-by-step process to promote BIMbased e-submission is required. For example, the process might be divided into four levels, each level of which includes an advantage that can be used to simplify the current permit review process. (1) Level 1: The system can automatically provide corresponding checklists of regulations or codes used during building permit reviews (this level can be implemented without BIM technology). (2) Level 2: The system can automatically produce corresponding regulations or codes and drawings based on the BIM-based e-submission project, and this project can be conveniently examined by reviewers. (3) Level 3: The system, combined with regulation or code databases and computation models, can automatically provide an autocheck function used to review BIM-based building projects. (4) Level 4: The system can automatically simulate the building conditions and environments supported by BIM technology (e.g., urban impact simulation, building disaster prevention, and building performance simulation) and provide an autocheck function for building permit reviews.

\section{Conclusions}

BIM has been regarded as one of the most critical IT innovations in the AEC and FM industries worldwide. To adapt to the BIM trend and improve industrial competitiveness, the Taiwanese government is developing a BIM-based e-submission system for building permit reviews. Before the system launch, the opinions, doubts, and concerns of industry participants must be seriously considered. Therefore, this paper presents the results of an investigation into the current status of BIM adoption in 300 Taiwanese architectural firms. In addition, an organizational readiness and technology acceptance assessment model were developed to determine firm to adopt BIM. Finally, a predictive model based on the ANN method was proposed to evaluate the feasibility of BIM adoption.

The findings and implications of this study pertaining to the proposed research objectives are summarized as follows. Regarding BIM acceptance, approximately twothirds of Taiwanese architectural firms lacked awareness and training in BIM-based e-submission, even though nearly half perceived the benefits of adopting BIM, such as improved communication efficiency, enhanced information exchange quality, innovative design, and new business expansion. Their willingness to adopt BIM was influenced by government policies $(53 \%)$, competitor motivation $(93 \%)$, and financial incentives and technological support $(60 \%)$.

Regarding organizational readiness, most firms have adopted a wait-and-see attitude, reflecting the industry's reluctance to change existing practices and hesitation to learn new concepts and technologies. In addition, closed 
organizational cultures, high switching costs, and limited training and technology support contributed to the unreadiness to adopt BIM. More time and incentives are required to facilitate BIM adoption in Taiwan.

The developed predictive model was tested using real cases, and was determined to be effective and reliable. Decision makers in architectural firms and potential BIM users who have not adopted BIM can use the model to critically evaluate the feasibility of adopting BIM in the future. The model is a critical decision support tool that can be utilized to promote and facilitate BIM application in the industry.

This pilot study identified several characteristics and conditions of BIM adoption in the Taiwanese architectural firms. Considering the government role and responsibility, BIM-based e-submission for building permit reviews will not be launched for some time. The government must first provide structured training support, establish an industrial standard format and infrastructure to facilitate information exchange, formulate BIM adoption roadmaps, and develop effective precedents to dispel doubts. In the industry, firms must adopt an attitude conducive to organizational readiness for change. Once the organizational readiness level increases, firms will be more willing to accept technology, leading to a virtuous cycle for competitors and participants in industries that are more willing to adopt BIM.

Because of limited time and resources, this study had certain limitations. First, the survey focused only on architectural firms. Future research could expand the range of interviewees (to clients, contractors, and engineers) and compare the diverse concerns regarding BIM adoption and BIM-based e-submission, providing a more comprehensive view of industrial development. Second, the assessment was based on Taiwanese industry conditions. Some adjustments of the assessment and predictive model are necessary to consider the regulations, cultures, and requirements in other areas. However, the experiences of firms in Taiwan might benefit firms facing similar situations and challenges in other countries.

\section{Acknowledgements}

The authors appreciate the valuable comments from editors and anonymous reviewers. Their detailed comments helped to improve the clarity and focus of this study. The authors are also grateful for the funding from the Ministry of Science and Technology, Republic of China (Taiwan) under project NSC 99-2221-E-011-088-. Special gratitude is extended to those architects who have responded to and contributed their valuable input in completing the questionnaire.

\section{References}

Arayici, Y.; Coates, P.; Koskela, L.; Kagioglou, M.; Usher, C.; O'Reilly, K. 2011. Technology adoption in the BIM implementation for lean architectural practice, Automation in Construction 20(2): 189-195.

https://doi.org/10.1016/j.autcon.2010.09.016
Ashurst, C.; Freer, A.; Ekdahl, J.; Gibbons, C. 2012. Exploring IT-enabled innovation: a new paradigm?, International Journal of Information Management 32(4): 326-336. https://doi.org/10.1016/j.ijinfomgt.2012.05.006

Assegaff, S.; Hussin, A. R. C.; Dahlan, H. M. 2011. Perceived benefit of knowledge sharing: adapting TAM model, in International Conference on Research and Innovation in Information Systems (ICRIIS), 2011, Kuala Lumpur, Malaysia. https://doi.org/10.1109/icriis.2011.6125744

Azhar, S. 2011. Building information modeling (BIM): trends, benefits, risks, and challenges for the AEC industry, Leadership and Management in Engineering 11(3): 241-252. https://doi.org/10.1061/(ASCE)LM.1943-5630.0000127

Bechky, B. A. 2003. Sharing meaning across occupational communities: the transformation of understanding on a production floor, Organization Science 14(3): 312-330. https://doi.org/10.1287/orsc.14.3.312.15162

Becker, F. 2004. Offices at work: uncommon workspace strategies that add value and improve performance. JosseyBass.

Boukamp, F.; Akinci, B. 2007. Automated processing of construction specifications to support inspection and quality control, Automation in Construction 17(1): 90-106. https://doi.org/10.1016/j.autcon.2007.03.002

Davis, F. D. 1989. Perceived usefulness, perceived ease of use, and user acceptance of information technology, MIS Quarterly: Management Information Systems 13(3): 319-339.

Eastman, C.; Lee, J. M.; Jeong, Y. S.; Lee, J. K. 2009. Automatic rule-based checking of building designs, Automation in Construction 18(8): 1011-1033.

https://doi.org/10.1016/j.autcon.2009.07.002

Godoe, P.; Johansen, T. S. 2012. Understanding adoption of new technologies: technology readiness and technology acceptance as an integrated concept, Journal of European Psychology Students 3: 38-52. https://doi.org/10.5334/jeps.aq

Goedert, J. D.; Meadati, P. 2008. Integrating construction process documentation into building information modeling, Journal of Construction Engineering and Management 134(7): 509-516. https://doi.org/10.1061/(ASCE)07339364(2008)134:7(509)

Harty, C. 2005. Innovation in construction: a sociology of technology approach, Building Research and Information 33(6): 512-522. https://doi.org/10.1080/09613210500288605

Howard, R.; Björk, B. C. 2008. Building information modelling - experts' views on standardisation and industry deployment, Advanced Engineering Informatics 22(2): 271280. https://doi.org/10.1016/j.aei.2007.03.001

Jarvenpaa, S. L.; Staples, D. S. 2000. The use of collaborative electronic media for information sharing: an exploratory study of determinants, The Journal of Strategic Information Systems 9(2-3): 129-154.

https://doi.org/10.1016/S0963-8687(00)00042-1

Kaplan, R. S.; Norton, D. P. 1992. The Balanced Scorecard: measures that drive performance, Harvard Business Review 70(1): 71-79.

Khazanchi, D. 2005. Information technology (IT) appropriateness: the contingency theory of "FIT" and IT implementation in small and medium enterprises, Journal of Computer Information Systems 45(3): 88-95.

Kim, K.; Yu, J. 2014. Improvement of BIM-based building approval system, in International Conference on Advances in Civil, Structural and Methanical, 2014, London, UK.

King, W. R.; Marks, P.; McCoy, S. 2002. The most important issues in knowledge management, Communications of the ACM 45(9): 93-97. http://dx.doi.org/10.1145/567498.567505

Kumar, R.; Aggarwal, R. K.; Sharma, J. D. 2013. Energy analysis of a building using artificial neural network: a review, Energy and Buildings 65: 352-358. https://doi.org/10.1016/j.enbuild.2013.06.007 
Kuo, Y. L. 2013. Technology readiness as moderator for construction company performance, Industrial Management \& Data Systems 113(4): 558-572. https://doi.org/10.1108/02635571311322793

Lee, S.; Yu, J. 2013. Effects of intrinsic and extrinsic motivation factors on BIM acceptance, Journal of the Korea Institute of Building Construction 13(3): 242-252. https://doi.org/10.5345/JKIBC.2013.13.3.242

Lee, S.; Yu, J.; Jeong, D. 2015. BIM acceptance model in construction organizations, Journal of Management in Engineering 31(3), 04014048. https://doi.org/10.1061/(ASCE)ME.1943-5479.0000252

Lin, C. H.; Shih, H. Y. Sher, P. J. 2007. Integrating technology readiness into technology acceptance: the TRAM model, Psychology \& Marketing 24(7): 641-657. https://doi.org/10.1002/mar.20177

Lin, W. T.; Shao, B. B. M. 2000. The relationship between user participation and system success: a simultaneous contingency approach, Information and Management 37(6): 283-295. https://doi.org/10.1016/S0378-7206(99)00055-5

Lin, Y. C. 2014. Construction 3D BIM-based knowledge management system: a case study, Journal of Civil Engineering and Management 20(2): 186-200. https://doi.org/10.3846/13923730.2013.801887

Ling, F. Y. Y.; Liu, M. 2004. Using neural network to predict performance of design-build projects in Singapore, Building and Environment 39(10): 1263-1274. https://doi.org/10.1016/j.buildenv.2004.02.008

Mahamadu, A. M.; Mahdjoubi, L.; Booth, C. A. 2014. Determinants of building information modelling (BIM) acceptance for supplier integration: a conceptual model, in Proceedings of the $30^{\text {th }}$ Annual ARCOM Conference, 2014, Portsmouth, UK.

Patterson, K. A.; Grimm, C. M.; Corsi, T. M. 2003. Adopting new technologies for supply chain management, Transportation Research Part E: Logistics and Transportation Review 39(2): 95-121. https://doi.org/10.1016/S1366-5545(02)00041-8

Rezgui, Y.; Beach, T.; Rana, O. 2013. A governance approach for BIM management across lifecycle and suupply chains using mixed-modes of information delivery, Journal of Civil Engineering and Management 19(2): 239-258. https://doi.org/10.3846/13923730.2012.760480

Rezgui, Y.; Hopfe, C. J.; Vorakulpipat, C. 2010. Generations of knowledge management in the architecture, engineering and construction industry: an evolutionary perspective, Advanced Engineering Informatics 24(2): 219-228. https://doi.org/10.1016/j.aei.2009.12.001
Samuelson, O.; Björk, B. C. 2013. Adoption processes for EDM, EDI and BIM technologies in the construction industry, Journal of Civil Engineering and Management 19(Supplement 1): s172-s187. https://doi.org/10.3846/13923730.2013.801888

Singh, V.; Gu, N.; Wang, X. 2011. A theoretical framework of a BIM-based multi-disciplinary collaboration platform, Automation in Construction 20(2): 134-144. https://doi.org/10.1016/j.autcon.2010.09.011

Taylor, J. E. 2007. Antecedents of successful three-dimensional computer-aided design implementation in design and construction networks, Journal of Construction Engineering and Management 133(12): 993-1002.

https://doi.org/10.1061/(ASCE)0733-9364(2007)133:12(993)

Tsai, M. H.; Mom, M.; Hsieh, S. H. 2014. Developing critical success factors for the assessment of BIM technology adoption: part I. Methodology and survey, Journal of the Chinese Institute of Engineers 37(7): 845-858. https://doi.org/10.1080/02533839.2014.888811

Tsikriktsis, N. 2004. A technology readiness-based taxonomy of customers a replication and extension, Journal of Service Research 7(1): 42-52. https://doi.org/10.1177/1094670504266132

Venkatesh, V. 2000. Determinants of perceived ease of use: integrating control, intrinsic motivation, and emotion into the technology acceptance model, Information Systems Research 11(4): 342-365. https://doi.org/10.1287/isre.11.4.342.11872

Weiner, B. J. 2009. A theory of organizational readiness for change, Implement Science 4(1): 67-75. https://doi.org/10.1186/1748-5908-4-67

Wong, A. K. D.; Wong, F. K. W.; Nadeem, A. 2011. Government roles in implementing building information modelling systems: comparison between Hong Kong and the United States, Construction Innovation 11(1): 61-76. https://doi.org/10.1108/14714171111104637

Xu, H.; Feng, J.; Li, S. 2014. Users-orientated evaluation of building information model in the Chinese construction industry, Automation in Construction 39(1): 32-46. https://doi.org/10.1016/j.autcon.2013.12.004

Zhang, X.; Mao, X.; AbouRizk, S. M. 2009. Developing a knowledge management system for improved value engineering practices in the construction industry, Automation in Construction 18(6): 777-789.

https://doi.org/10.1016/j.autcon.2009.03.004 


\section{Appendix A}

Technology acceptance survey

\begin{tabular}{|c|c|c|c|c|c|c|}
\hline \multirow[b]{3}{*}{ Dimensions } & \multirow[b]{3}{*}{ Questionnaire items } & \multicolumn{5}{|c|}{ Likert scale } \\
\hline & & 1 & 2 & 3 & 4 & 5 \\
\hline & & 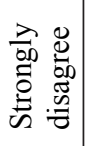 & 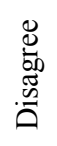 & $\frac{\bar{d}}{\stackrel{ \pm}{0}}$ & 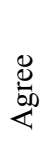 & 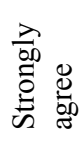 \\
\hline $\begin{array}{l}\text { BIM technology } \\
\text { transmission }\end{array}$ & $\begin{array}{l}\text { 1. I am now using BIM software for work-flow operation } \\
\text { 2. I am willing to join the BIM experience program }\end{array}$ & & & & & \\
\hline $\begin{array}{l}\text { External Environment: } \\
\text { conditions and factors } \\
\text { influencing the organi- } \\
\text { zation's BIM-related } \\
\text { activities, adoption, } \\
\text { opportunities and risks }\end{array}$ & $\begin{array}{l}\text { 3. I am satisfied with the current building permit review process } \\
\text { 4. I think BIM is helpful toward current building permit review process } \\
\text { 5. I desire to use BIM in future building permit review process } \\
\text { 6. I think BIM can improve the efficiency of business communication } \\
\text { 7. I think BIM can improve owner satisfaction } \\
\text { 8. I think BIM is helpful to resolve construction disputes } \\
\text { 9. I think BIM is helpful to clarify drawings } \\
\text { 10. I will like to adopt BIM if other competitors have adopted it } \\
\text { 11. I think BIM is helpful to develop new types of business }\end{array}$ & & & & & \\
\hline $\begin{array}{l}\text { Employees: staff } \\
\text { adoption of BIM and } \\
\text { workload reduction }\end{array}$ & $\begin{array}{l}\text { 12. I think employees are willing to accept BIM adoption } \\
\text { 13. I think it is easy to operate BIM for employees } \\
\text { 14. I think BIM can improve workload reduction over the long term }\end{array}$ & & & & & \\
\hline $\begin{array}{l}\text { Internal factors: } \\
\text { improving workflow } \\
\text { efficiency }\end{array}$ & $\begin{array}{l}\text { 15. I think BIM can improve the efficiency of existing processes } \\
\text { 16. I think BIM can reduce operating costs } \\
\text { 17. I think BIM can reduce firm's operating costs } \\
\text { 18. I think BIM can improve the exchange of quality drawings } \\
\text { 19. I think BIM can improve and upgrade firm' software and hardware } \\
\text { 20. I think BIM can improve communication quality } \\
\text { 21. I think BIM can improve innovation and development of architectural } \\
\text { design } \\
\text { 22. I think BIM can improve organizational learning }\end{array}$ & & & & & \\
\hline
\end{tabular}

\section{Appendix B}

Organizational readiness survey

\begin{tabular}{|c|c|c|c|c|c|c|c|c|}
\hline \multirow{2}{*}{ Dimensions } & \multirow{2}{*}{ Questionnaire items } & & \multicolumn{5}{|c|}{ Semantic scale } & \\
\hline & & & 1 & 2 & 3 & 4 & 5 & \\
\hline Leadership & $\begin{array}{l}\text { 1. CEO's leadership and executive power } \\
\text { 2. CEO's leadership style on workplace } \\
\text { 3. CEO views the need for change to use BIM }\end{array}$ & $\begin{array}{l}\text { passive } \\
\text { authoritative } \\
\text { unimportant }\end{array}$ & & & & & & $\begin{array}{l}\text { proactive } \\
\text { charismatic } \\
\text { critical }\end{array}$ \\
\hline $\begin{array}{l}\text { Business } \\
\text { performance }\end{array}$ & $\begin{array}{l}\text { 4. The integrity of the organizational structure } \\
\text { 5. The complexity of construction business type } \\
\text { 6. Financial soundness }\end{array}$ & $\begin{array}{l}\text { incomplete } \\
\text { simple } \\
\text { unsound }\end{array}$ & & & & & & $\begin{array}{l}\text { complete } \\
\text { complex } \\
\text { sound }\end{array}$ \\
\hline $\begin{array}{l}\text { Operating } \\
\text { environment }\end{array}$ & $\begin{array}{l}\text { 7. Hardware support } \\
\text { 8. Willingness to invest in new equipment } \\
\text { 9. Development of operation database }\end{array}$ & $\begin{array}{l}\text { unsupported } \\
\text { unwilling } \\
\text { unsound }\end{array}$ & & & & & & $\begin{array}{l}\text { supported } \\
\text { willing } \\
\text { sound }\end{array}$ \\
\hline $\begin{array}{l}\text { Organizational } \\
\text { culture }\end{array}$ & $\begin{array}{l}\text { 10. Culture of organization values risk-taking } \\
\text { 11. Sharing of information and ideas } \\
\text { 12. Business and design innovation }\end{array}$ & $\begin{array}{l}\text { low } \\
\text { low } \\
\text { conservative }\end{array}$ & & & & & & $\begin{array}{l}\text { high } \\
\text { high } \\
\text { innovative }\end{array}$ \\
\hline $\begin{array}{l}\text { Technical } \\
\text { environment }\end{array}$ & $\begin{array}{l}\text { 13. Technology support from colleagues } \\
\text { 14. Continuous education and training for employees } \\
\text { 15. Supply chain management }\end{array}$ & $\begin{array}{l}\text { low } \\
\text { poor } \\
\text { poor }\end{array}$ & & & & & & $\begin{array}{l}\text { high } \\
\text { excellent } \\
\text { excellent }\end{array}$ \\
\hline Workforce & $\begin{array}{l}\text { 16. Employees' computer ability or technology acceptance } \\
\text { 17. Employees already have BIM technology ability } \\
\text { 18. Firm's staff turnover percentage }\end{array}$ & $\begin{array}{l}\text { low } \\
\text { low } \\
\text { high }\end{array}$ & & & & & & $\begin{array}{l}\text { high } \\
\text { high } \\
\text { low }\end{array}$ \\
\hline
\end{tabular}


Yi-Kai JUAN. He is Dr, an Associate Professor at Department of Architecture, National Taiwan University of Science and Technology (NTUST), Taipei, Taiwan. He was a post-doctoral research fellow at Building Construction Program, Georgia Institute of Technology in 2008 and a visiting scholar at Center for Sustainable Development and Global Competitiveness, Stanford University, California in 2009. His recent research interests include sustainable development, strategic property and facility management, industry analysis, and decision support system in $\mathrm{A} / \mathrm{E} / \mathrm{C}$ industries.

Wan-Ying LAI. She is Dr, an Assistant Professor at Industrial Design, Ming Chi University of Technology (MCUT), New Taipei City, Taiwan. Her recent research interests include spatial hyperlink design, design education, interaction design, smart buildings, and computer aided design.

Shen-Guan SHIH. He is Dr, a Professor and chair at Department of Architecture, National Taiwan University of Science and Technology (NTUST), Taipei, Taiwan. His recent research interests include BIM practices, smart buildings, and computer aided design. 